\title{
The Role of Music in Speech Intelligibility of Learners with Post Lingual Hearing Impairment in Selected Units in Lusaka District
}

\author{
Emily Mwamba Katongo, Daniel Ndhlovu* \\ Department of Educational Psychology, Sociology and Special Education, The University of Zambia, Zambia
}

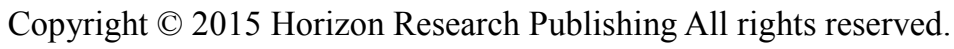

\begin{abstract}
This study sought to establish the role of music in speech intelligibility of learners with Post Lingual Hearing Impairment (PLHI) and strategies teachers used to enhance speech intelligibility in learners with PLHI in selected special units for the deaf in Lusaka district. The study used a descriptive research design. Qualitative and quantitative research methods were used. A total of 100 respondents participated in the study. Simple random and purposeful sampling procedures were used to select respondents. The study found that music played a significant role in enhancing speech intelligibility as it motivated learners during speech drills. It also helped in clearing the vocal cord, facilitating verbal memory, widening vocabulary, improving word pronunciation and sentence construction leading to speech intelligibility acquisition. The study also identified several strategies that teachers used to help learners acquire speech intelligibility and these include use of total communication, encouraging lip reading, use of amplification devices among other techniques. On the basis of the study findings, it was recommended that; teachers should use music in speech training of learners with PLHI. The Ministry of Education Science Vocational training and Early Education (MESTVEE) need to modify classrooms with acoustically treated walls and fit amplification devices, speech mirrors and other necessary equipment specifically designed to meet educational needs.
\end{abstract}

Keywords Speech Intelligibility, Post Lingual Hearing Impairment

\section{Background of the Study}

Hearing problems seem to be the most common sensory deficits in human populations, with hearing loss alone affecting more than 250 million people worldwide (Mothers and Loncar 2006). In 2008, World Health Organisation (WHO) estimated that over 360 million persons in the world had disabling hearing loss. This constituted $5.3 \%$ of the world population, nearly 183 million adult males above 15 years old and 145 million females, which was $7.5 \%$ of the adult male population and approximately $6 \%$ of the adult female population respectively. With the ageing of the world population these numbers were expected to double by 2030-2050. Hearing impairment is considered the most prevalent impairment worldwide (Duthey, 2013). According to the Zambia Ministry of Finance (2000) census report, there were about 256,000 disabled people in Zambia, out of which $6.2 \%$ were deaf. This translates into about 15,915 deaf people. Out of these figures, $12.4 \%$ were hard of hearing translating into about 31,830 hard of hearing people. Out of these estimates, no specific reference was made to people with Post Lingual Hearing Impairment (PLHI). People with post lingual hearing impairment are those with a condition of deafness that occurred after acquiring language. However PLHI are found among all levels of hearing impairment except among the profoundly deaf. The word deaf in this study refers to a condition that do not allow a child to hear sounds or speech while hard of hearing is a condition that allows a child to hear a bit of sound but relying on amplification devices to make sense out of the sound heard. The term residual hearing implies that to a very small extent a child can hear sound of speech. A child with residual hearing may also be referred to as being hard of hearing. Thus a child with post lingual hearing impairment is one whose deafness occurred after acquiring language.

Due to the escalating levels of hearing impairment, recent years are witnessing an increasing enrollment of learners with special needs in schools worldwide. For instance, Hallahan \& Kauffman (1994) reported that over 4 million special needs learners were identified in various public schools of United States. By 2000, the number had risen to over 5.7 million (Heward, 2000). Wakumelo and Miti (2010) reported that the deaf people were one of the least educated people in Zambia and that there were 14,233 hearing impaired persons who were five years old and above in the year 2000. According to the Ministry of Finance (2000) only 
$28.1 \%(1,167.1)$ of the estimated number of these hearing impaired children had been to primary school and only $8.2 \%$ (3999.5) had reached secondary school. These figures show that only 4,675.5 hearing impaired learners were in school in 2000. However, just as has been reported in other countries, the enrolment of Hearing impaired learners has also increased in Zambian schools for an obvious reason that the educational policy emphasizes education for all regardless of one's disability. Through the 1996 policy document, the Ministry of Education Science, Vocational Training, and Early Education (MESVTEE) stresses the need to ensure that there is equality of educational opportunities for children with special educational needs. The policy further emphasizes the need to provide education of particularly good quality to pupils with special educational needs (Ministry of Education 1996).

The MESVTEE also encourages integration of children with special educational needs to the greatest extent possible into the mainstream schools especially those with mild hearing impairment and with residual speech. Residual speech refers to intelligible speech that remains in a deaf person after most of what he/she acquired deteriorates as a result of deafness. Learners with post lingual hearing Impairment (PLHI) have residual but distorted speech. Davis and Mac Neilage (1995) pointed out that although learners with post lingual hearing impairment (PLHI) had residue spoken language, their speech deteriorated with time if no intervention to enhance it was put in place. Poor speech intelligibility was noted in their poor word pronunciation, unclear sentence articulation and intonation and poor sentence construction. The greater the extent of these patterns of errors, the poorer the speech intelligibility and the less the hearing impaired speakers are understood by listeners unfamiliar with the child.

Poor speech intelligibility was observed in most learners with post lingual hearing Impairment (PLHI) in Lusaka District. Similarly, in a study conducted by Mulonda (2013), at Magwero in Chipata and at Saint Joseph in Kalulushi districts of Zambia, it was observed that most learners with hearing impairment had poor speech intelligibility and this made communication between them and teachers very difficult. To this effect, teachers communicated with hearing impaired children using either sign language or signed English. However, according to Davis and Mac Neilage (1995), speech during the initial periods of hearing loss, required practicing abilities in children with PLHI because if these children are exposed to Sign language or Signed English at an early stage, they begin to use these manual languages at the expense of their residual spoken language. This leads to progressive loss of speech intelligibility. As a consequence, most hearing-impaired children must be taught the speech skills that normal-hearing children readily acquire during the first few years of life. For this reason, oral communication skills of hearing-impaired children have long been a concern to educators in Lusaka province.

Currently there is no literature in Zambia on how learners with PLHI are being helped to retain and enhance intelligible speech. Pezo (2013) in Mwinilunga district in Zambia evaluated instructional strategies used by pre-school teachers in presenting Reading Readiness Activities to pre-scholars and music was found to be one of the strategies used in helping learners master and pronounce difficulty words. This improved their speech intelligibility. However, this study was done on children with normal hearing and normal speech hence could not specifically fill up the knowledge gap related to learners with hearing impairment in Zambia. Never the less, there is still evidence to support use of Musical therapy as an effective treatment with individuals who have communication impairments resulting from brain injury or other neurological trauma. For example, Magee, Brumfitt, Freeman \& Davidson, (2006) used Musical therapy to improve and sustain speech of clients who suffered left hemisphere brain damage. The study also noted that Darrow (1989) in Germany used music to train students with pre-lingual hearing loss in speech. Results showed that they were able to improve in word pronunciation and articulation making their speech quite intelligible and wondered whether use of music in speech training of learners with PLHI would produce similar results hence this study.

\subsection{Statement of the Problem}

Poor speech intelligibility in pupils with post lingual hearing loss raises concern because their residue spoken language deteriorated with time. The researchers observed the deterioration in their word pronunciation, unclear sentence articulation and poor intonation which had a negative impact on their oral communication. Consequently, it made their speech difficult to be understood by listeners. While the researchers pondered how to address this problem in Zambia, they noted that Darrow (1989) used music to train students with pre-lingual hearing loss in speech in Germany. Results showed that they improved in word pronunciation, articulation and intonation thus making their speech quite intelligible. What was not known was whether use of music in speech training would enhance speech intelligibility in learners with post lingual hearing loss in the selected special units for the deaf in Lusaka district of Zambia. This study therefore sought to establish whether use of music in speech training could enhance speech intelligibility in learners with post lingual hearing loss.

\subsection{Purpose of the Study}

The purpose of this study was to establish the role of music in enhancing speech intelligibility in learners with post lingual hearing impairment.

\subsection{Research Objectives}

The study was guided by the following objectives:

1. To establish the role of music in speech intelligibility of learners with Post lingual hearing impairment in selected special units for the deaf in Lusaka district. 
2. To explore strategies teachers used to enhance speech intelligibility in learners with post lingual hearing impairment in selected special units for the deaf in Lusaka district.

\subsection{Significance of the Study}

It was hoped that the findings of this study may add to the body of knowledge on the role of music in speech intelligibility in learners with post lingual hearing impairment. It was also hoped that the findings of this study may stimulate further studies and provide empirical support for future research in the field of speech in learners with post lingual hearing impairment. Expected beneficiaries to this study might be learners with post lingual hearing impairment in that use of music in speech training may enhance their speech intelligibility and benefit from the New Break-Through to literacy (NBTL) which helps students to learn a second language (English) faster. These findings might also be of help to MOESVTEE in coming up with new speech interventional programmes in schools. The findings may also help Curriculum developers to develop musical materials likely to improve speech training of learners with post lingual hearing impairments. Teachers too might benefit from this study because music might enhance speech intelligibility in learners with PLHI leading to improved communication and higher academic performance in learners.

\section{Literature Review}

This section presents related literature reviewed on the role of music in speech intelligibility of learners with PLHI. The literature is in line with study objectives which were to: establish the role of music in speech intelligibility of learners with PLHI and to explore strategies teachers used in enhancing speech intelligibility in these learners.

Abercrombie (1949:120) defined speech intelligibility as a pronunciation which can be understood with little or no conscious effort on the part of the listener. Several pronunciation proponents have reaffirmed his view that as long as a listener is able to understand what the speaker is trying to convey, that speech is intelligible for example, Dalton \& Seidlhofer (1994) shared this same view. On the other hand, Kenworthy (1987:13) described comfortably intelligible as being understood by a listener at a given time in a given situation and equated it with 'understandability.

Concerning the role music played in enhancing intelligible speech, Ho et al. (2003) found out that music training affected the development of learners' brains in a specific pattern. They noted that individuals with music training tended to have enlarged left temporal lobes. In addition, they pointed out that portion of the brain was also thought to mediate verbal memory.

Darrow (1989) reported that use of music in speech therapy worked well in addressing speech intelligibility by improving vocal intonation, vocal quality and speech fluency. He further explained that the breathing processes, rhythmic timing requirements, pitch and articulation needed for singing songs provided important structure and motivation for the clients. In addition, he stated that laughing giggling and singing offered good auditory stimuli to the early developing mind. Based on the available literature, the researcher still remained wondering as to the role of music in enhancing speech intelligibility of learners with post lingual hearing impairments.

As regard strategies used to enhance speech intelligibility, Branon (1994) used amplification devices such as hearing aids and spoke through a microphone in an acoustically treated room and children were meant to imitate his pronunciations of words. He observed that 20 to 25 per cent of their words in their practical speech were intelligible to listeners who were unfamiliar with hearing impaired child's diction. In a similar study, after using amplification devices on $58 \mathrm{HI}$ learners, Markides (1970) found that about $31 \%$ of their words were intelligible to their teachers and $19 \%$ were intelligible to native listeners. Reviewed literature so far still does not fill up the knowledge gap about the role of music in speech intelligibility of learners with post lingual hearing impairment in Zambia's schools. This knowledge gap became the motivating factor to conducting this study.

\section{Methodology}

Since the study sought to use both quantitative and qualitative methods to describe the role of music in speech intelligibility of learners with post lingual hearing impairment, a descriptive survey design was chosen. Quantitative and qualitative research paradigms were chosen because of their complementary roles. McGraw (2002) defines a qualitative design as the collection and analysis of non-numerical data for the purpose of gaining insights into a phenomenon of interest. The qualitative method allowed the researcher to conduct interviews and the non-participant observations. The quantitative paradigm was chosen to collect quantitative data. The sample comprised of 80 respondents of which 60 were learners with PLHI at basic school (grades 1 to 9), and 20 were their teachers. Simple random sampling procedure was used to select pupils as it gave them equal chance to be part of the study. Purposeful sampling procedure was used to select the teachers. This procedure was chosen because it these teachers were the ones with the characteristics needed for the study. Semi structured questionnaires were used to collect both qualitative and quantitative data from the teachers while interview schedules and observation checklist were used to collect qualitative data from the pupils. The 60 pupils were grouped in experiment and control groups. Thus each group had 30 pupils. Before commencement of the speech intervention, the words in the song Jesus loves me were written for pupils on the chalk board. Pupils were then given two tests. One test was on single word pronunciation and 
another on short sentence construction. These pretests were conducted to establish the baseline performance of pupils before music as an intervention was introduced to the experimental group. The experimental group was then drilled in singing the song and rhyming the words orally until they gained competence. Others were the ' $A B C D$ ' song which was used to teach pupils letters of the alphabet, 'one man and a dog' song to teach the concept of addition and subtraction and the 'Sunday Monday 'song to teach about days of the week. The researchers then randomly selected the words in the song and wrote them on the chalk board. Pupils were drilled in oral word pronunciation and sentence construction. To the control group, same words in the song "Jesus loves me" was used without singing them. Pupils were drilled in word pronunciation and sentence construction.

After six months of drills using music, their speech intelligibility was measured. Pupils were given two tests. One test was on single word pronunciation and the other was on short sentence construction. Ten words were presented to individual pupils to read them orally while being recorded by the researchers. Listeners not familiar with speech of hearing impaired pupils were given to listen to the recordings and write down the word as they heard and felt the speaker meant. If the listener wrote the correct word, it meant that the pupil' speech was intelligible, for example the word Jesus, a pupil who pronounced it as Jijashi and the listener heard it as Jesus, was considered intelligible speech than a pupil who read it as Jii or Jaja. For the word mother, a pupil who read it as maza and the listener took it for mother was considered have made an intelligible speech than a child who read it as mee, moo, modoor mojo.

To ensure reliability of the results, researchers used instrument triangulation, for instance, a semi structured questionnaire, interview schedule and observations were used to collect data from the respondents. Ethical issues were considered by obtaining informed consent from the teachers and parents of pupils and keeping the identity of respondents anonymous.

\section{Findings and Discussion}

The study found out that music in speech training motivated learners and further revealed that pupils with hearing impairment were able to hear musical vibrations, thus the beat in the instruments stimulated them. Since pupils with PLHI were reported to have low self-esteem due to speech distortion, it may not be easy to encourage them to talk. Therefore use of music in speech training may help since music evokes emotions and mirrors the main characteristics of emotional behaviour, speech and thought.

The study also discovered that the beat in singing helped pupils in regulating their speech patterns. Music helped pupils in this way, most likely because speech was musical since it had rhythmic patterns and pitch, all which may be noted in intonation, stress and articulation. To this effect,
Calvert (1989) reported that music may regulate and improve sentence production because it was known to have a pattern of movements similar to speech. Singing followed a rhythm and had pitch. Most learners with hearing impairment had no speech rhythm and this prevented listeners from understanding them. Therefore singing helped pupils with PLHI acquired rhythmic speech patterns. Supporting this view is Gfeller (1986) who reported that rhythm and pitch patterns can assist a client in learning articulation and pronunciation of words and improve speech rhythms, accents, and sentence phrasing.

The study also revealed that pupils with residual hearing were able to mimic singers. Therefore, if pupils can mimic good singers who are good speakers, they too may produce good speech. Learning a language through music seems easy especially that people easily learn songs even in foreign languages. In support of this view, Parncutt and Levitin (2001) reported that everyone understood music despite lack of declarative knowledge about it.

The study highlighted that 'music speaks' and words sung stuck in pupils' minds as they listened to a song repeatedly. The study also reported that pupils felt that music helped them to remember and master words in a song. Considering that most pupils with hearing impairment suffered from short memory span, teachers may be right to use music as Levitin (2006) reported that multiple reinforcing cues of a good song, rhythm, melody and contour caused music to stick in the minds of pupils. Thus music formed a tool for activation of specific thoughts. Perhaps this was the major reason teachers used music to teach certain concepts. For example, the ' $A B C D$ ' song was used to teach pupils letters of the alphabet, 'one man and a dog' song to teach the concept of addition and subtraction and the 'Sunday Monday 'song to teach about days of the week. These songs helped in mastering these concepts. In line with this, Wolf and Horn (1997) reported that music was a mnemonic device which was usually used to remember formulas.

In addition the study revealed that singing helped learners to clear the vocal fold and allowed the inflow of air into speech organs. It was further elaborated that air helped in producing explosive and fricative sounds. Similarly a study by Robins (1990) highlighted that the flow of music also gave exercise to speech organs, for example; singing induced the sound box into vibrations, vocal fold was adjusted in length, tension and shape. Thus, singing gave the human larynx the honors for vocal versatility that helped in appreciating the musicality in every day speech. The finding is also in tandem with Robbin (1980) who discovered that music reinforced vocal spontaneity, improved voice quality, and gave a freer use of rhythmic principles.

The study also revealed that music widened pupils' vocabulary in that as they listened more and more to music, they learnt more words. Gfeller, (1986) similarly stated that music assisted in the development of vocabulary and had the advantage of patterned drill without monotony. In addition, since singing had a repetitive nature, it acted as a drill in which pupils learnt speech through singing the song words. 
This was made possible because music contained tempo whose speed typically generated excitement, energy and action. Its sudden change also captured attention of pupils and produced maximum suspense during which a teacher introduced a concept requiring maximum attention.

The study also discovered that music was very useful in auditory training because it helped pupils to differentiate sounds. In this way, they were able to acquire speech. Teachers said that sound awareness and differentiation facilitated production of intelligible speech. This finding is consistent with Darrow (1985) who reported that music offered a medium through which listening can be practiced. $\mathrm{He}$ further stated that children must be taught to become aware of sounds as a means of obtaining information from their environment. Hence sound discrimination did not only facilitate speech acquisition but also reading. Pupils with PLHI mainly depend on visual communication and reading was one of them. Speech was enhanced through reading. This was done by writing down words intended for speech training. The words were recited or rhymed and later on used for learning stress, articulation and intonation. Teacher may even introduce music to teach stresses as tapping, clapping, or playing simple rhythm instruments helps pupils to be aware that unstressed syllables have weak beats and that to their vowels beat needed to be reduced.

Teachers also indicated that music improved speech intelligibility as it helped in word pronunciation, sentence construction and intonation. This finding was in line with Robbins (1980), who reported that among other benefits, the potential contribution of music therapy was evident in the quickening of the individual's overall learning of pronunciation and intonation. The finding seemed to indicate that singing was a tool that facilitated speech probably because of its movement quality, likely to evoke movement of the larynx, jaw, tongue and lip leading to proper speech production. In order to empirically establish whether music enhanced word pronunciation and sentence construction, the study conducted an experiment on two groups of learners. One group was given music as treatment in speech training while the other was not. Pre-tests in single word pronunciation and sentence construction were also conducted to establish the baseline threshold of pupils' speech intelligibility before the treatment. They were asked to read the words and sentences orally before any of them received treatment of music and plain oral drills. Although results show that both groups performed poorly, the control group performed better than the experimental group during the pre-test in that the majority of the pupils could not read more than five (5) words out of ten in single word speech intelligibility test or above four (4) sentences out of eight (8) sentences. After the experiment, results in the post-test showed that pupils in the experimental group out performed learners in the control group in both, single word pronunciation and short sentence construction intelligibility tests. $20(67 \%)$ out of 30 pupils in the experimental group orally read more than five words intelligibly as opposed 11 $(37 \%)$ of the 30 pupils in the control group. Details are in figure 1.

Average performance in single word intelligibility in both groups was established using a t-test. The mean score in a single word intelligibility for the control group was 2.7 better than the 2.3 for experimental group in the pre-test. As regards the post-test, the mean score in single word intelligibility for the experimental group was 4.9 better than the 3.7 in the control group. This result implies that music contributed to the pupils' speech intelligibility. The mean score difference in the pre-test between the control and experimental group was 0.4 and 1.2 in the post test. In the pre-test the control group had a higher mean while the experimental group had a higher mean in the post-test. On the basis of these mean scores, the researchers argue that music has positive role in speech intelligibility in pupils with post lingual hearing impairments. See statistical details shown in table 1.

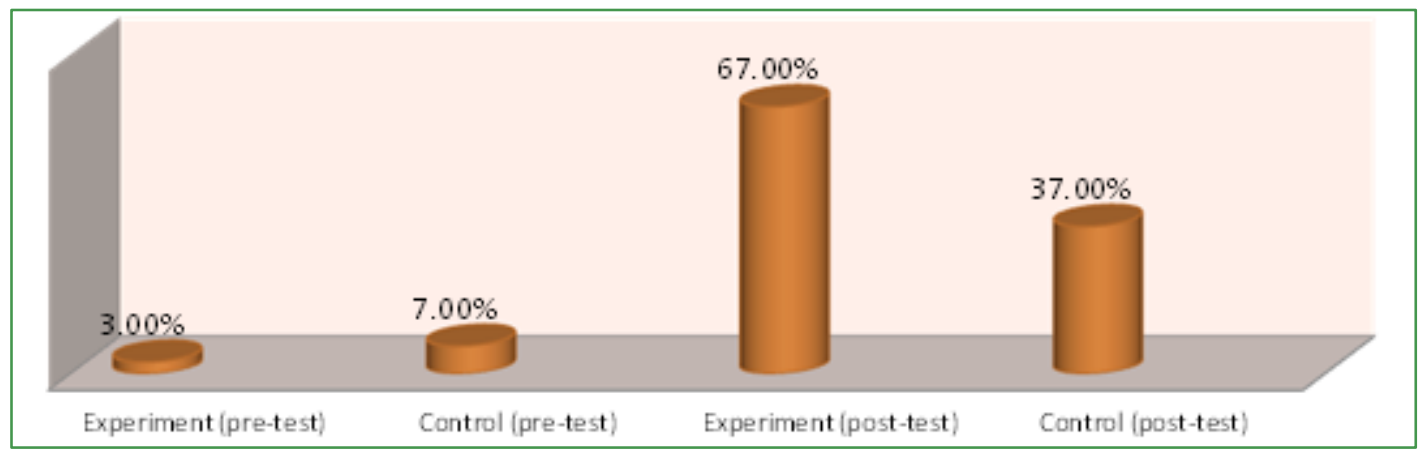

Figure 1. Pre-test and Post-test Summary performance

Table 1. Pre-test and Post-test Single Word Intelligibility Test Mean Scores

\begin{tabular}{|c|c|c|c|c|c|c|}
\hline \multicolumn{7}{|c|}{ Paired Samples Statistics } \\
\hline group & & $\mathrm{N}$ & Minimum & Maximum & Mean & Std. Deviation \\
\hline Experimental & Pre-test & 30 & 1.00 & 5.00 & 2.3000 & 1.08755 \\
Control & Pre-test & 30 & 2.00 & 5.00 & 2.7667 & 1.04000 \\
\hline Experimental & Post-test & 30 & 2.00 & 8.00 & 4.9333 & 1.46059 \\
Control & Post-test & 30 & 1.00 & 5.00 & 3.7000 & 1.17884 \\
\hline
\end{tabular}




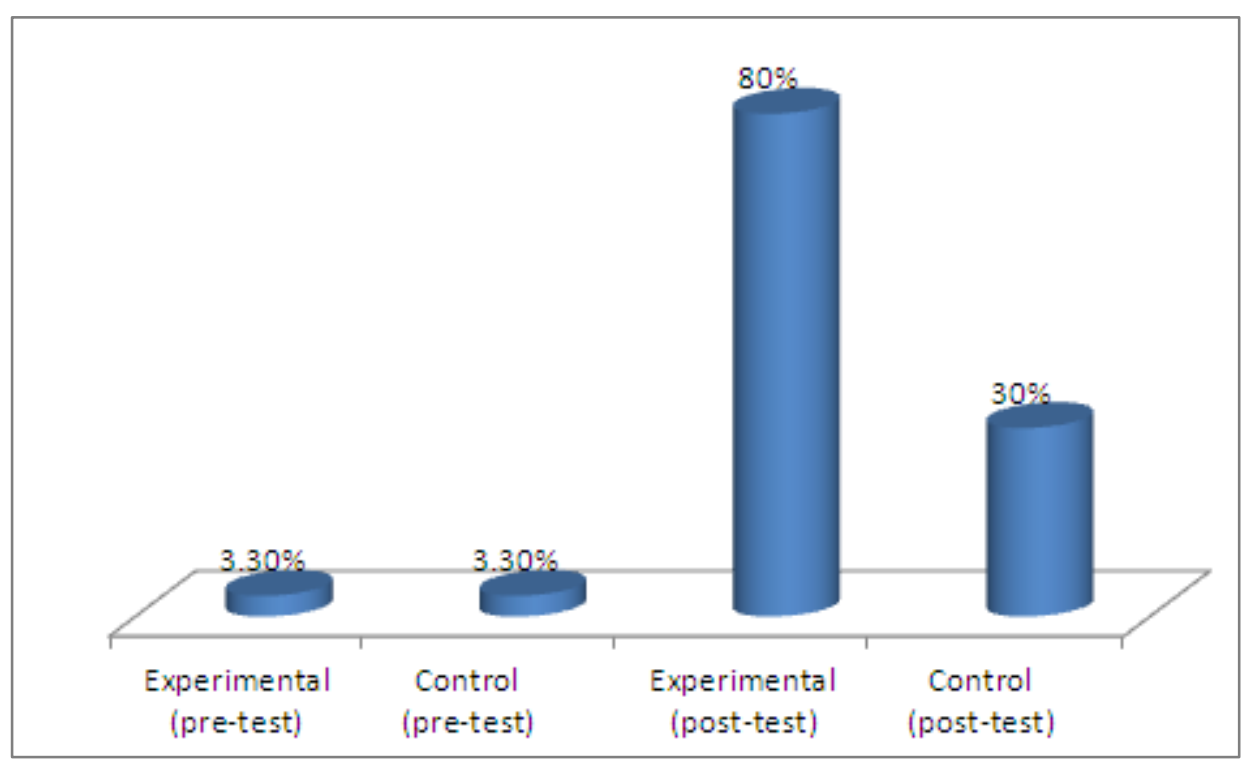

Figure 2. Experimental and Control group Short Sentence Construction Test Results

Table 2. Average performances in Short Sentence Construction Test

\begin{tabular}{|c|c|c|c|c|c|c|}
\hline Group & Test & $\mathrm{N}$ & $\begin{array}{c}\text { Minimum number of } \\
\text { sentences read }\end{array}$ & $\begin{array}{c}\text { Maximum number of } \\
\text { sentences read }\end{array}$ & Mean \\
\hline Experimental & Pre-test & 30 & 1.00 & 4.00 & 1.6000 \\
\hline Control & Pre-test & 30 & 1.00 & 4.00 & 1.6000 \\
\hline Experimental & Post-test & 30 & 1.00 & 8.00 & 4.4667 \\
\hline Control & Post-test & 30 & 1.00 & 5.00 & 2.6333 & 1.43198 \\
\hline Valid N & & 30 & & & 1.27261 \\
\hline
\end{tabular}

Coming to short sentence construction test, both groups performed poorly in the pre-test. However, after treatment, the experimental group outperformed the control group. Thus, $24(80 \%)$ out of 30 pupils in the experimental group performed better as opposed to $9(30 \%)$ of the 30 pupils in the control group. Again these results imply that music played a positive role in speech intelligibility of the learners. Details are in figure 2.

Using a t-test, mean scores in short sentence construction test were established between the experimental and control groups in both the pre-test and post-test. Results show that in both groups the mean was 1.6 in the pre-test and 4.5 and 2.6 in the post-test for the experimental and control groups respectively. The experimental group had a higher mean score $(80 \%)$ as opposed the $30 \%$ mean score for the control group. These results suggest that music in speech training enhanced speech intelligibility in pupils with PLHI. Details are in table 2.

The difference was statistically significant $(\mathrm{p}<. .000)$ implying that music had a positive influence in enhancing speech intelligibility in pupils with post lingual hearing impairment.

\section{Strategies Teachers Used in Enhancing Speech Intelligibility in Pupils with PLHI}

The second objective was to establish strategies teachers used to enhance speech intelligibility in pupils with hearing impairment. The study discovered that teachers used amplification devices, lip reading, total communication and a combination of these to enhance speech intelligibility.

The study noted that teachers encouraged lip reading because most of these learners lost the sense of hearing after developing speech, so it was easy for them to perceive what someone was saying by following lip movements. This method was encouraged because it was the initial process for learning speech and language since babies learnt speech by observing the lip of their caregivers. Supporting this view are Lewkowicz et al (2013) who discovered that between ages of six to eight months, during the "babbling" stage of language acquisition, babies focused on the mouth of the speaker and they continued lip reading until about 10 months of age, at which they switched their attention back to the eyes. However, much as this method may be popularly considered adequate, it had its own limitations. For instance, sounds whose places of articulation were deep inside the mouth or throat are not detectable. The glottal consonants and most gestures of the tongue are such examples. Voiced and unvoiced pairs look identical such as $[\mathrm{p}]$ and $[\mathrm{b}]$, [g], [t] and [d],[f] and [v], and [s] and [z]; likewise, for nasalization [m] vs. [b]. It has been estimated that only $30 \%$ to $40 \%$ of sounds in the English language were distinguishable from sight alone (Lewkowicz et al (2013). To this effect it may be 
concluded that lip-reading was not adequate enough in enhancing speech intelligibility in learners with PLHI.

In addition the study found out that other teachers encouraged speaking and signing at the same time to help pupils develop intelligible speech. Educators and parents may favor this strategy probably because it is a 'catch-all' that ensures that a deaf child has access to some means of communication. For example, a deaf child who cannot communicate well orally got the additional support of sign language, and vice versa. However depending entirely on this method of communication posed a risk as signing became more prominent than speech and this resulted in less developed speech skills. Probably this was the reason pupils' speech was unintelligible despite use of total communication.

The study also reported that teachers encouraged pupils to imitate their parents and teachers as they were considered to be speech role models. This finding is consistent with Girolametto et al, (1996) who reported that facilitative language technique, such as imitation and expansion, enhanced language learning in young children at the single-word stage of language development. Naturally, parents were the first teachers of speech because children started learning speech by imitating parents. However, this method was not always reliable because as children grew up, they often drifted away from parents in preference to peers who too may be deaf hence, the need to find a better method of enhancing speech intelligibility.

In addition, the study reported that teachers felt that role play in classrooms of pupils with PLHI needed to be encouraged as it helped pupils to use residual speech. In addition, findings show that teachers felt that, using wall pictures in story telling helped pupils to improve their speech as it encouraged them to orally narrate of the story in the picture. By so doing pupils developed confidence in using oral communication. To this effect pupils need to be placed according to grade and level of impairment otherwise pupils who cannot speak intelligibly may be discouraged if they placed in the same classrooms with those who have hearing and with no speech difficulties.

\section{Conclusions}

Based on the findings, the study concludes that music played a significant role in enhancing speech intelligibility in pupils with PLHI by facilitating verbal memory, widening vocabulary, clearing vocal cords, improving pronunciation, intonation and sentence construction.

\section{Recommendations}

Based on the findings the following were recommended:

1. To help learners improve speech intelligibility, teachers should use music in speech training.
2. The Ministry of Education needs to procure musical instruments to enhance speech lessons in classrooms.

3. Teachers should not dwell on the usual lip-reading and total communication (speech and signing) which have this far not helped much but must always be creative and plan musical speech training so as to meet pupils' educational needs.

\section{REFERENCES}

[1] Abercrombie (1949) Effects of singing classes on pupils with hearing impairments. New York: University Press

[2] Alexander N (2002). Bilingual education as a transitional strategy in post-colonial Africa. Cape Town: PRAESA.

[3] Bakare, C.A. (1988). Audiological assessment of the Nigerian child. Ibadan: Fountains Books.

[4] Brannon, J.R. (1994). 'Visual Feedback of Glossal Motions and its Influence on the Speech of Deaf Children'. Unpublished doctoral dissertation. Northwestern University.

[5] Calvert, D.R. (1989). 'Some Acoustic Characteristics of all the Speech of Profoundly Deaf Individuals'. Un published doctoral dissertation, Stanford University.

[6] Dalton \& Seidlhofer (1994). 'Effect of music on depression levels and physiological responses in community-based older adults'. Oxford University Press: Amazon.

[7] Darrow, A. (1989). Music therapy in the treatment of the hearing-impaired. Music Therapy Perspectives, 6, 61-70.

[8] Davis, B.L., \& MacNeilage, P.F. (1995). The articulatory basis for babbling. Journal of Speech and Hearing Research, 36(6), 1199-1211.

[9] Duthey, B. (2013). Priority Medicines for Europe and the World: A public health approach to innovation. www.who.int/medicines/areas/priority-medicines/BP6-21He aring.pdf visited on $6 / 4 / 15$.

[10] Gfeller, K.E. (1986). Musical mnemonics for learning disabled children. Teaching Exceptional children. Fall, 28-39.

[11] Girolametto L.E, Pearce P.S., Weitzman E. Interactive focused stimulation for toddlers with expressive vocabulary delays. J Speech Hear Res 1996;39:1274-84

[12] Gold, T. (1980). Speech production in hearing- impaired children. Journal of Communication Disorders; 13. 397-418

[13] Hallahan, D.P. \& Kauffman, J.M. (1994).'Exceptional Children: Introduction to Special Education'. Allyn \& Bacon: USA.

[14] Heward, L.W. (2000). 'An Introduction to Special Education'. Merrill/Pearson: London.

[15] Ho, Y.C., Cheung, M.C., \& Chan, A.S. (2003). 'Music Training Improves Verbal but not Visual Memory: Cross-sectional and Longitudinal Explorations in Children'. Neuropsychology, 17, 439-450.

[16] John, D. (1994). The Pronounciation of English. Cambridge: University Press. 
[17] Kenworthy (1987) Therapeutic role of music listening in stroke rehabilitation. Annals of the New York Academy of Sciences.

[18] Lewkowicz et al (2013) (http://www.pnas.org/content/early/ 2013). Visited on $4 / 3 / 2014$

[19] Parncutt, R. and Levitin D. J. (2001). Absolute pitch. In the New Grove Dictionary of Music and Musicians (Sadie, S. ed.), pp. 37-39, Grove

[20] Levitin, J.D., (2006). This is your Brain on Music: The Science of Human Obsession. Penguin Group (USA): New York

[21] Magee, W. L., Brumfitt, S. M., Freeman, M., \& Davidson, J. W. (2006). The role of music therapy in an interdisciplinary approach to address functional communication in complex neuro-communication disorders: A case report. Disability and Rehabilitation, 28(19), 1221-1229.

[22] Markides A. (1970).The speech of Deaf and Partially-hearing children with special reference to factors Affecting intelligibility. British Journal of disorders of communication, 5, 126-140

[23] McGraw, R. (2002). "Studies in Social Sciences Research" New York: CBS College Publishing.

[24] Mothers, C.D. \&Loncar, D. (2006).Projections of Global Mortality \& burden of disease from 2002 to 2003 PIOS Med 3(11): e442

[25] Ministry of education (1996), 'Educating our future'. Lusaka: Ministry of Education
[26] Ministry of Finance (2000). Census Report 2000. Lusaka: Central Statistics Office.

[27] Ministry of Finance (2010), Census Report 2010. Lusaka: Central Statistics Office

[28] Mothers, C.D. \& Loncar, D. (2006). 'Projections of Global Mortality \& Burden of Disease from 2002 to 2003'. PIOS Med 3(11): e 442.

[29] Mulonda M. (2013) 'A Situational Analysis of Sign Language in the Education of the Deaf in Zambia'. A Case of Magwero and St Joseph School for the Deaf. University of Zambia Lusaka.

[30] Pezo, K. (2013). An Evaluation of instructional strategies pre-school teachers use to present reading readness activities to prepare pre-schoolers for grade one reading in Kabompo and Solwezi districts of Northwestern province of Zambia; www.university of zam/E:library@unza.zm. visited on $2 / 2 / 14$.

[31] Robin. J., (1980). An Intelligibility study of tracheoesophageal punctures. Paper presented at Annual Convention of American Speech - language hearing Association. Detroit.

[32] Wakumelo N.M. \& Miti L. (2010), 'A Journey into the Deaf world: Issues of Language and Culture'. Paper Presented at the African Languages Association for Southern Africa (ALASA) Conference, University of Botswana

[33] Wolf. C., and Horn, D. (1997). Speech and language development in children with hearing impairments. Hawthorne: New York 